\title{
Can't We All Just Get Along?
}

Question: If [Senator] Ted Cruz and [Speaker of the House]

John Boehner were both on a sinking ship, who would be saved?

Answer: America.

-Politico columnist Roger Simon, during the federal government shutdown, October 20I3 (Simon 20I3)

On the surface, the shutdown of the federal government in October 2013 was driven by a minority of members of the US House of Representatives who prioritized the defense of their ideological beliefs over the desires of a majority of legislators, a popularly elected president, and an increasingly frustrated electorate. This may be disturbing enough, but dig a little deeper into the underlying layers that enabled this remarkable political stalemate, and an even more worrisome picture emerges.

After all, part of what allowed Tea Party Republicans to challenge the implementation of Obamacare through hardball tactics, including the threat (and reality) of a government shutdown, was their influence over the restructuring of congressional districts following the 2010 censuspartly because of the Republican victories in 2010 national and state races. With large majorities in state houses, conservative legislators drew up districts so secure for those on the right that many elected officials were more likely to face viable political opposition from a Tea Party flank in Republican primaries than from Democrats in the general election. But while this gerrymandering of districts reflects a sort of politics gone crazy, it is really just one instance in a longer-term process: the spatial sorting of the American public.

Though deeply rooted patterns of racial segregation seem to be declining slightly, broader patterns of separation by income and political affiliation seem to be increasing. And it's not just space. Changes in our media landscape are reinforcing the social fragmentation that results 
from this sorting into more economically and politically homogeneous neighborhoods. The decline in readership of daily newspapers and the increasing narrowcasting of cable and online media sources means that a common knowledge base of what is going on in daily society is being further eroded. Not only are our political leaders in Washington unable to govern together, but increasingly large sectors of the general population can't even agree on whether the climate is changing, whether immigration helps or hurts, or any number of issues on which actual evidence might be helpful.

This fragmentation in the very knowledge base that fortifies both public life and social norms is exacerbated by the underlying increase in economic inequality. The shift in incomes and wealth toward the richest among us has created another sort of epistemological chasm, between one group on top, who believe they got there through their own efforts, and another group down the income chain, who wonder when (and if) their efforts will ever pay off (Piketty 20I4; Stiglitz 20I2). In the past, economic growth helped smooth over both distributional and political tensions; when all boats are rising, people are a bit less concerned about who has a yacht and who has a raft. But when the economy seems stalled-as it did in the wake of the Great Recession-a country can find itself in a vicious cycle. As Harvard economist Benjamin Friedman put it in early 2013 , "we could be stuck in a perverse equilibrium in which our absence of growth is delivering political paralysis, and the political paralysis preserves the absence of growth" (quoted in Lowrey 2013).

Yet there may be lessons for the future if we look at the way in which strategies to grow the economy, address inequality, and reduce political fragmentation vary across our national landscape. After all, certain metropolitan regions have shown particular resilience even in the face of sharp economic restructuring. The reasons behind their performance are complex and often rooted in a number of structural factors, such as the sectoral mix of their regional economy, the educational level of their workforce, and the scale and role of public employment-all of which have impacts on economic growth and the distribution of income. None of these are easy to change quickly. Industrial diversity is hard to secure, educational capabilities improve slowly over time, and local public sectors, long suffering as the nation has moved toward more market-oriented strategies, are in many places still reeling from the impacts of the Great Recession.

But another element may be more susceptible to action: the development of diverse and dynamic epistemic communities. It's a clunky term, 
we know, but epistemic community actually has an intuitive meaning: it's what you know and who you know it with. While the evidence is still tentative (and this book is an attempt to move the ball forward on that front), our research suggests that such communities-ones that are diverse in their membership and sources of knowledge, and dynamic in their ability to withstand shocks, continuously learn, and adjust over time-can actually help construct and sustain regional social norms that facilitate the achievement of growth, resilience, and inclusion (Benner and Pastor 2012). In short, our ability to grow together may be fundamentally rooted in our ability to know together.

\section{CRISIS AND CHALLENGE: A NATIONAL PERSPECTIVE}

So what is it that we need to know? Perhaps the most important thing is that the economic and social problems we are facing as a nation go well beyond the contemporary statistics on unemployment and GDP growth rates-and the solutions therefore require going beyond the usual tinkering with tax rates, spending patterns, or even job-training funds and strategies. This is because the downturn that manifested itself in late 2008 was actually rooted in several very long-term and interrelated challenges: the jobs crisis, the inequality crisis, and the political crisis.

\section{The Jobs Crisis}

The recovery following the Great Recession was characterized, at least until 2014 , as a "jobless recovery," a term that certainly resonated with the lived experience of ordinary workers. This was not a new phenomenon. Slow job growth has followed the end of the recession in the last three economic recoveries. However, from I96I through the I980s, job growth began immediately with the end of the recession. By three years after the beginning of the recovery, total jobs had increased by over 7 percent in all the recoveries that lasted that long, and by Io percent in three cases. In contrast, in all three of the most recent business cycles (starting in I99I), it took more than a year into the economic recovery for job growth to begin at all. By three years into economic recovery, in no case was total job growth greater than 4 percent, and it took six full years just to recover to pre-recession employment levels from the 2008 recession-which was still less than what would be needed to keep up with the growth in the labor force.

Some analysts suggest that this experience of "jobless recovery" since the I990s is the result of the increased diffusion of information 
technology throughout the economy, as higher levels of productivity have enabled companies to produce more goods and services with fewer people and more machinery, robots, and computers (Autor, Katz, and Kearney 2006; Brynjolfsson and McAfee 20II). This argument, however, ignores the widespread evidence, both in the United States and abroad, that the overall impact of technology on job and wage levels is indeterminate-that it depends on a variety of other factors, including trade patterns, exchange rates, and education policies, that shape the overall relationship between technology diffusion and job creation (Bogliacino and Vivarelli 20I0; C. L. Mann 20I 2; Mortensen and Pissarides I998).

It also seems clear that our economy is experiencing not simply a jobs shortfall but also a dramatic period of economic restructuring, with some evidence that this is accompanied by a long-term slowdown in economic growth rates. In the decades of the I950s and I960s, the US economy experienced average annual growth rates of over 4 percent. This dropped to an average of 3 percent in the I970s, '80s, and '9os. In the 2000s, average overall economic growth was only $\mathrm{I} .6$ percent a year, while in the first four years of the 2010 , it was 2 percent a year. ${ }^{1}$ Rapid population growth had something to do with these numbersthe baby boom was a substantial economic boost for the country in the I950s and '60s-but even adjusting for total population, per capita growth rates in recent decades have also slipped when compared to earlier decades.

\section{The Inequality Crisis}

We have also experienced a dramatic growth in income inequality in recent decades. Using data from the Internal Revenue Service, Emmanuel Saez and Thomas Piketty have demonstrated that from the r940s up to the late I970s, the proportion of total income in the United States captured by the top ro percent of income earners consistently remained in the 33-35-percent range (Piketty and Saez 2003). Starting in I979, however, upper income earners started gaining consistently higher proportions of total income, which rose to a peak of a full 50.4 percent of all income going to the top Io percent of income earners in 20I 2. And much of this was concentrated in the top I percent, which saw its proportion of total US income rise from roughly ro percent, between the I940s and I98I, to a high of 23.5 percent in 2007 (with a slight fall to 22.5 percent in 20I2; Atkinson, Piketty, and Saez 20II). ${ }^{2}$ 
This growth in inequality has many roots, including excessive CEO and executive compensation at the top of the income ladder, as well as excessive financialization, leading to outsize returns in the financial sector (Stiglitz 20I2). But it is also due to stagnant and declining wages for large sectors of the workforce, partly because of large shifts in returns to education. While real hourly wages grew an average of 2.6 percent per year between I 948 and I973, they grew only 0.2 percent per year in the I970s, 0.8 percent per year in the I980s, 0.3 percent per year in the I990s, and 0.9 percent per year in the 2000s. ${ }^{3}$ Between 1973 and $201 \mathrm{I}$, wages fell by more than 20 percent for workers with less than a high school degree, more than 7 percent for workers with only a high school degree, and nearly 5 percent for those with some college education. In 1973, these categories accounted for a full 95 percent of the labor force, and even by 20II, a full 66 percent of the labor force still had less than a college degree and was receiving wages that were lower in real terms than nearly 40 years previously. ${ }^{4}$

As Piketty (20I4) has argued, the distributional problem is exacerbated by a lack of economic growth. When growth is slow but profit rates remain high, capital's share of income accumulates-and with it, the ability of capital to exercise influence in the economic policymaking process. That, in turn, exacerbates the very shifts in tax policy and financial market openness that have helped generate income and wealth inequality in the first place (Alvaredo et al. 20I3). Again, we find a sort of vicious cycle-and it is one made worse by the lack of political leadership seeking to effectively address the deep crises of slow job creation and rising inequality.

\section{The Political Crisis}

Alongside these economic and distributional challenges has been a crisis in our political institutions that is nearly unparalleled in the nation's contemporary history (Mann and Ornstein 20I2). Prior to the November 20I4 elections, approval ratings of President Barack Obama were nearly the lowest of his term. But most striking has been the long-term decline in the percentage of the American electorate approving of the way Congress is handling its job. ${ }^{5}$ In one poll conducted in early $20 \mathrm{I}_{3}$, following the gridlock over the "fiscal cliff" and a particularly unproductive I I 2 th congressional session, only 9 percent of respondents had a favorable opinion of Congress (Easley 2013). ${ }^{6}$ The Gallup Poll of Americans' level of approval of Congress, probably the most reliable and 
consistent source of data to compare public opinion over time, found average approval ratings from $20 \mathrm{II}$ to $20 \mathrm{I} 3$ to be the lowest in the 40 years over which comparable data has been gathered, with consistently less than 15 percent of Americans approving of the way Congress was doing its job (Newport 2013).

Like the challenges facing our economy, this is not a recent phenomenon. Despite a brief surge following the 9/I I attacks, overall confidence in political institutions has declined from highs in the I960s. Meanwhile, voter participation rates fell steadily over the two decades following the mid-I960s, with turnout of eligible voters averaging about 40 percent in mid-term elections for the past forty years $(\mathrm{McD}$ Donald 20IO). The lack of confidence-and interest-is not surprising. Rather than addressing pressing issues, our leaders seem to be stumbling from crisis to crisis, from news cycle to news cycle, from a dismal yesterday to an uncertain future.

One bit of evidence: Congress has become less and less effective at moving legislation, even as it has become more effective at partisan bickering (McCarty, Poole, and Rosenthal 2006).7 Party-unity scores, which measure the percentage of members voting with a majority of their party, have risen from levels of roughly 75 percent in the I970s to around 90 percent in the most recent years (Ornstein et al. 20I3). The polarization grows from-and feeds directly into-what we think is the most important underlying factor: a dramatic decline in consensus on basic facts needed for policymaking, such as the role of taxation in economic growth, the impact of immigrants on society, and even the nature of global warming.

Part of the reason for that increasing fragmentation of knowledge is an increase in narrowcasting in the media. Since the I970s, we have experienced a growing customization of media channels and fragmentation of news sources, starting first with the growth in cable television and accelerating dramatically with the growth of the Internet (Owen 20I2). Readership of daily newspapers has declined across all age groups; particularly striking is that less than 30 percent of adults age I 8-34 read a daily newspaper, whether in print or on the Web. ${ }^{8}$ Meanwhile, with the acceleration and increasing sophistication of algorithmbased customization of Internet-based information-on sites as varied as Google, Facebook, Amazon, and the New York Times-information that is "unwanted" is increasingly filtered out without the consumer even knowing (Pariser 20II). 
We have also seen an increase in spatial sorting by both partisan ideology and social class. More people seem to be moving to areas with more homogeneous political and social circumstances, and thus are exposed to less diversity of opinions in their residential life as well (Chinni and Gimpel 20II). In I976, for example, only about a quarter of America's voters lived in a county where a presidential candidate won by a landslide (20 percent or more); by 2004 , it had grown to nearly half (Bishop and Cushing 2008), and by 20I2, more than half the voters lived in such landslide counties. ${ }^{9}$ As for class isolation, in I970, only I 5 percent of families were in neighborhoods that were classified as either affluent or poor. By 2007, this had more than doubled, to 3 I percent of families (Reardon and Bischoff 20II).

Information fragmentation and spatial sorting has, we believe, eroded a common base of knowledge about the very nature of the problems we face as a nation-both in the political leadership and in the broader public that elects them. For example, in a July $20 \mathrm{I} 2$ poll by the Pew Forum on Religion and Public Life, 30 percent of Republicans said that they thought that President Obama is Muslimnearly double the percentage who thought so four years previously. ${ }^{\text {Io }}$ Similarly, more than a third of respondents in a 2006 survey by Ohio University believed that federal officials either assisted in the 9/I I terrorist attacks or took no action to stop them so that the United States could go to war in the Middle East. ${ }^{\text {II }}$ While these examples could make for a lighthearted chuckle about the extremes in the political spectrum, we worry that they are evidence of a deeper challenge facing the nation. When we can't agree on the basic facts, disagreement about appropriate solutions-and sharp but ill-informed ideological warfare-are sure to follow.

\section{Connecting the Crises}

Many observers seem to see the jobs crisis, the inequality crisis, and the political crisis as relatively disconnected. This implies that they could either be dealt with separately or, to the extent that they are connected, sequentially. However, we believe that these three crises are in fact deeply interconnected-and that the starting point for addressing all three has to be shrinking the epistemic distance that allows us to believe that we are living in separate and disconnected worlds in which we are each entitled to not only our own beliefs but our own facts. 
There is, for example, an emerging consensus that inequality and economic stagnation, particularly in terms of employment, are linked. The new and highly influential research by Thomas Piketty (20I4) suggests that more rapid growth tends to more generally rebalance power between social classes and income groups, and weaken the grip on politics of those with inherited wealth. The relative prosperity in the latter part of the Clinton administration, for example, raised workers' bargaining power and also brought a narrowing of racial wage differentials that had not been seen since the early days of the civil rights breakthroughs.

But while this notion that growth can change the power balance is somewhat familiar, a more novel concept has emerged in economic thinking in recent years: the idea that inequality might itself damage prosperity and economic sustainability. The reasons why equity might have an impact on growth are complex-but not inaccessible. For one thing, inequality may be associated with lower demand and excessive financialization of the economy, particularly as the wealthy look for more creative (and more risky) ways to hold their assets. Inequality is also corrosive to social solidarity, creating political problems when it comes time to share either burdens or benefits (Frank 20I2; Stiglitz 20I2).

Both slow growth and inequality are also closely linked with our political crisis. The growth part is evident-when the labor market is slack and there is less to go around, tensions can rise. But in an intriguing paper, political scientist Eric Uslaner (20I2) also suggests that inequality has an impact on the ability to reach political consensus. Running a series of multivariate regressions in which measures like trust and social cohesion were considered dependent variables while various measures of inequality and other control measures were entered as the independent variables, he found that not only is rising inequality a significant predictor of low levels of trust and social cohesion, it also explains a large share of the shifts (e.g., up to a third of the decline in a generalized measure of trust between the late I960s and the current era).

A rise in income inequality, as measured by the Gini coefficient, has also been shown to be associated with a decline of faith in government institutions, as well as a fall in the sense that different racial groups share common interests. Of course, these various trends may be moving in the same direction because of an entirely different third factor common to them all-but the relation between growing inequality and growing social distance makes intuitive sense to those who have 
observed the growth of gated communities, the rise of exurbia, and the continued geographic concentration of racial minorities and the poor (Kneebone, Nadeau, and Berube 20I I).

Why does this matter? When everyone is far apart in terms of both income and perspective, sensible agreements on tax policy, education investments, and industrial promotion are difficult to achieve. We need to address the jobs, inequality, and political crises at the same time, but the very social distance rendered by slow growth, slipping opportunity, and polarized politics makes it hard to move forward. However, while reversing this downward spiral may seem like a tall order, we don't actually need to start from scratch. There are lessons emerging from a handful of regions across the country which, over a sustained period of time, have been able to create not just growth but just growth-that is, economic expansion that weds prosperity and inclusion.

And while that fortunate coincidence of enhanced output and improved distribution is certainly connected to key structural factorslabor-market tightness, locally rooted firms, and booming industrieswe suggest in this volume that there is another element that often plays a complementary role: the ability of regions to foster conversation, overcome civic fragmentation, and find the policy "sweet spots" where what seem like two sides of a divide become the interdependent yin and yang of a singular whole.

\section{COMING TOGETHER: LESSONS FROM AMERICA'S} REGIONS

The idea that a better national approach can bubble up from America's metropolitan regions has gained increased currency in recent years. Part of the reason for this "rise of the region" is the idea that it is the relevant unit for an internationalized economy-the scale at which economies of scale can be achieved to lower production costs while business networks can be maximized to facilitate innovation. Another part of the reason is simply the frustration with the stasis in Washington and the willingness of regional leaders to try new ideas to spur recovery and restructuring (Katz and Bradley 20I3). Finally, the variability in regional fortunes-along with some evidence that this variability has been increasing in recent decades (discussed in chapter 3 as well as by Pastor, Lester, and Scoggins 2009) - suggests that a careful attention to the processes shaping this variation might yield valuable insights for action at different scales. 
Indeed, the emerging notion that inequality might actually damage economic growth seems to have gained the most ground at the metropolitan level. In certain places, key regional actors-including collaboratives of business, labor, civic, and community leaders-have become increasingly convinced that a more inclusive economic approach can actually strengthen the social consensus and human capital needed to compete in a global economy. Backing up that perspective has been a range of empirical studies, including from the Federal Reserve, showing that strategies that reduce social, geographic, and other disparities are actually correlated with broad economic success (Eberts, Erickcek, and Kleinhenz 2006; Voith I998).

So how is this shift in economic thinking connected to the issue of political disconnection discussed above? Under what conditions do the imperatives of fairness and the need to support economic drivers come together at the metropolitan level? What are the social and political arrangements, particularly given the general lack of regional government, that allow this to happen in some regions and impede it in others? And what are the potential lessons for a nation seeking to stop the economic bleeding, shrink the distributional divisions, and, most of all, restore a sense of common fate?

\section{Learning from the Regions}

We offered an initial answer to these questions in our last book, Just Growth (2012). There, we relied heavily on a quantitative approach to identify those regions with above-median performance in terms of job growth and earnings increases, on the one hand, and poverty reduction and inequality improvement, on the other. We then conducted regressionstyle analysis to explore the demographic, political, and economic determinants behind these growth and equity patterns-and using the same database as that employed in the regression analysis, we then identified a set of seven regions for more in-depth case studies, suspecting that we might find through this a list of best practices to attain more equitable growth in metropolitan settings.

Researchers generally begin with hypotheses, and we did find some things we expected. Both the statistical and the qualitative work revealed the stabilizing effect of the public sector, the generally positive impact of deconcentrating poverty, the growth-enhancing but equityreducing impacts of having a large immigrant population, and the important role of an influential minority middle class that can bridge an 
interest in prosperity with a continuing commitment to fairness. But actually spending time in the field made us aware of a factor we had never even considered, and one we explore in great depth in this volume: the importance of efforts to create shared social norms in the form of what we now call epistemic communities.

Formally, epistemic communities have been defined as like-minded networks of professionals whose authoritative claim to consensual knowledge provides them with a unique source of power in decisionmaking processes (Adler and Haas I992; Haas I992). In our earlier work, we suggested that when the members of such knowledge communities include not just the "usual suspects" of urban-growth coalitions but a broader constellation of community interests and perspectives, regional trajectories might be affected. We specifically suggested that creating a diverse regional consciousness about the problems of poverty and its impacts on growth tends to focus attention; that interjurisdictional ties can help (because, for example, suburbs that can be annexed realize rather quickly that they cannot escape the drag on regional growth of high levels of poverty in the urban core); and that all this can be pushed along by intentional leadership programs and other strategies for collaborative governance.

We will admit to being initially hesitant to stress the role of political and governance processes. We both tend to lean toward economic and structural explanations. The idea that people just talking actually makes a difference was comforting in one sense (ideas do matter!) and discomforting in another (how do you measure this?). Still, while we remained uneasy with the concept, knowledge communities-and the leadership and other networks that produced them-did seem to make a difference to both the actors and the outcomes, and so we simply reported what we saw and hoped that the ideas would be fleshed out over time.

What we didn't anticipate is that the framework would attract both some significant attention (Reynolds 20I2) and some useful criticism (Lester and Reckhow 20I3). Perhaps the most important of the latter emphasized our seeming failure to account for conflict. After all, in the real world, business leaders are often deeply committed to an economic perspective in which labor unions slow growth, regulation impedes efficiency, and fairness is an afterthought to be taken up in one's charitable spare time. In contrast, community and labor leaders may be steeped in a framework wherein the economy is a site of exploitation, protection against insecurity is essential, and economic growth is someone else's 
concern. Conflicts can all get worse when political entrepreneurs jump into the stew, seeking to advance their own partisan interests by fueling divisions in the pursuit of short-term gain.

Moreover, conflict is not necessarily antithetical to achieving the goals of prosperity and inclusion. In what we thought was a very effective (albeit sympathetic) critique of our work and that of others, Lester and Reckhow suggested that regional progress on equity, particularly in light of generally weak metropolitan governance structures, should really be seen as advancing through a series of policy skirmishes between various actors. This is also the underlying perspective of Amy Dean and David Reynolds (2009), who argue that more inclusive growth will come only through the strengthening of central labor councils and the emergence of community-labor coalitions.

Yet another shortcoming was the impression we may have given that epistemic communities necessarily lead to more equitable growth-or perhaps better put, the shortcoming was our failure to specify causal mechanisms between community making, norm formation, and changes in the economy (Schildt 20I2). Of course, the connection is tentative. Intergroup understanding may facilitate growth and equity, but it is not likely to overcome the collapse of a major regional industry (although some of the cases in this volume suggest that it might stir regional action to mitigate the damage). Knowing together will not always produce growing together-but it can help.

\section{Learning in the Regions}

You don't always get a second crack at further specifying the case you are making-but sometimes life does produce such blessings. In our case, it was a grant from the Institute for New Economic Thinking that allowed us to further investigate the links between equity and growthand the role of knowledge communities in helping foster the connection between the two in the minds of regional actors.

We report on that research in this book, once again combining quantitative and qualitative analysis in a mixed-methods approach. As we detail below, we begin by offering some novel econometric work looking at the impact of both income distribution and various measures of social distance on the sustainability of employment growth (i.e., the relationship between inequality and the jobs crisis). We then explain how we chose a series of case-study regions, partly based on "just growth" outcomes and partly based on the presence of regional knowledge 
communities. We then walk through a range of cases: Sacramento and Salt Lake City, as two cases where formal collaborative planning processes have been key to producing a sense of common destiny; Charlotte, Grand Rapids, and Oklahoma City, as a set of cases where regional growth strategies have been mostly elite-driven; Greensboro, Fresno, and San Antonio, as places where conflict has raged-and in one case, eventually produced collaboration; and Raleigh, Seattle, and Silicon Valley, as locales where the knowledge economy meets what we have termed knowledge communities.

So what's new this go-around? In this effort, we expand our previous analysis in three ways. We stress more the process of community building than the impacts on growth and equity; we offer a fuller account of the ways in which conflict and collaboration can go together; and we add the characteristics of diversity and dynamism that our newest case-study research suggests are key to both sustainable communities and sustainable growth. While we explore the causal chains and the role of conflict below, it is useful to start by defining what we mean by a diverse and dynamic epistemic community at the metropolitan level. ${ }^{12}$

Our concept of diverse and dynamic epistemic communities builds initially from the work done on epistemic communities per se. The concept of an epistemic community was first developed throughout the I960s and I970s in the context of understanding the production of scientific knowledge, primarily by the sociologist Bukart Holzner (I968; Holzner and Marx 1979), though it owes some intellectual allegiance to Ludwik Fleck's (20I2) idea of a "thought collective" and Thomas Kuhn's (20I2) notion of a scientific community (see also Cross 20I3). John Ruggie (1972) introduced the term to the field of international relations, drawing on Foucault's (1970) notion of an episteme to define such a community as embodying "a dominant way of looking at social reality, a set of shared symbols and references, mutual expectations, and predictability of intention" (Ruggie I975).

The concept gained significant attention following work by political scientist Peter Haas in the early I990s on the challenges of coordinating international policy in light of increasing levels of complexity and uncertainty. Haas and his colleagues suggested that networks of knowledgebased experts can play an important role "in articulating cause-and-effect relationships of complex problems, helping states identify their interests, framing the issues for collective debate, proposing specific policies and identifying salient points for negotiation" (Haas I992, 2). In their work, 
Haas and his colleagues describe an epistemic community as a group of people that has four broad characteristics:

I. a shared set of normative and principled beliefs, which provide a value-based rationale for the social action of community members

2. shared causal beliefs, which are derived from their analysis of practices leading or contributing to a central set of problems in their domain and which then serve as the basis for elucidating the multiple linkages between possible policy actions and desired outcomes

3. shared notions of validity - that is, intersubjective, internally defined criteria for weighing and validating knowledge in the domain of their expertise

4. a common policy enterprise-that is, a set of common practices associated with a set of problems to which their professional competence is directed, presumably out of the conviction that human welfare will be enhanced as a consequence (Haas I992, 3).

In understanding the evolution of such epistemic communities, uncertainty and interaction are key. Poorly understood conditions make it more difficult to know which strategies are most likely to be successful, and with established procedures lacking, existing institutions are less effective at generating appropriate information and knowledge (Cross 20I3). The process of creating such knowledge together, particularly in a series of repeated interactions over extended periods of time, can help participants develop a common language and cognitive frames that allow them to communicate effectively and share new knowledge (Hakanson 2005). And while the literature does stress institutionalization and the link with a common policy enterprise, such communities are not necessarily limited to formal legislative or policy processes. As Adler and Haas (I992, 374) put it: "The policy ideas of epistemic communities generally evolve independently, rather than under the direct influence of government sources of authority." In short, epistemic communities are more about governance than about government.

\section{Complicating the Frame}

In developing our own notion of diverse and dynamic epistemic communities, we stress multiple ways of knowing. While Haas's approach privileges traditionally defined experts and theoretically oriented methods of knowledge production, we think there are at least two other broad kinds of knowledge that are valued in more diverse epistemic communities. 
One of these other kinds of knowledge is action-oriented, socially productive, and ethically rooted. It is not simply the practical knowledge that comes from the application of theoretical knowledge, but is a form of knowledge that incorporates a moral dimension about the purposes toward which that applied knowledge is being put, including the creation of and debate about ideal ends. Greenwood (2008) also identifies a third kind of knowledge, which involves the design of problem-solving actions through collaboratively developed knowledge that combines the local knowledge and interpretative strategies of stakeholders with professional researchers' knowledge.

These latter two features contribute to diversity and inclusion. Creating hybrid groupings of experts and lay people broadens the information base used to address problems and reduces the privileged position of experts while incorporating the real-world insights of those most affected by the decisions (Irwin and Michael 2003; Chilvers 2008). Diversity, in this sense, refers not simply to the racial or sectoral heterogeneity of the participants in a process of knowledge sharing but also to the recognition that at least certain types of knowledge are actually dependent on the full and equal participation of non-"expert" stakeholders in the earliest stages of issue framing and agenda setting.

In this broader framework, an epistemic community is not just about consensus, and it is definitely not a conflict-free zone. Indeed, as we stress later in our case study of San Antonio, community can actually emerge from conflict-and comity does not mean the end of tensions or "skirmishes" at a regional level (Lester and Reckhow 2013). But in high-performing regions, conflicts are attenuated by the recognition of a common regional destiny-a sense of place that makes tension an important learning opportunity rather than an invitation to further a long-term "war of attrition" (as seems to have been the case in, say, Greensboro or Fresno). This requires that participants develop social norms about how to engage in conflict, including an understanding of the "rules of the debate," a commitment to repeated interactions, and a sense of the ways in which data can and should be collectively used to shape decision-making processes. In at least one place, this even has a name. The famous "Seattle process" is a region-specific, culturally embedded way to solve conflicts that is viewed by many as tedious and time-consuming but is also valued as an effective method to reach consensus, with its latest most remarkable achievement being the 20I4 agreement between business, labor, and civic leaders on a \$ 5 -an-hour minimum wage. 
TABLE I.I CLASSIFYING EPISTEMIC COMMUNITIES

\begin{tabular}{|c|c|c|}
\hline & $\begin{array}{l}\text { Traditional view of } \\
\text { epistemic communities }\end{array}$ & Diverse and dynamic epistemic communities \\
\hline Membership & $\begin{array}{l}\text { Driven by experts and/ } \\
\text { or professionals }\end{array}$ & $\begin{array}{l}\text { Driven by leadership from diverse } \\
\text { constituencies, with broader notions of what } \\
\text { constitutes valid knowledge }\end{array}$ \\
\hline $\begin{array}{l}\text { Ties that } \\
\text { bind }\end{array}$ & Shared values/interests & $\begin{array}{l}\text { Sense of a common regional destiny, often } \\
\text { created through repeated interaction that } \\
\text { involves skirmishes and principled conflict as } \\
\text { well as collaboration }\end{array}$ \\
\hline $\begin{array}{l}\text { Ways of } \\
\text { knowing }\end{array}$ & $\begin{array}{l}\text { Common causal beliefs } \\
\text { and shared notions of } \\
\text { validity }\end{array}$ & $\begin{array}{l}\text { Acknowledgement of legitimacy of others' } \\
\text { viewpoints and information bases and } \\
\text { agreed-on norms of interaction and "rules of } \\
\text { the debate" (either explicit or implicit) }\end{array}$ \\
\hline $\begin{array}{l}\text { Scope of } \\
\text { goals }\end{array}$ & $\begin{array}{l}\text { Typically a common } \\
\text { policy enterprise }\end{array}$ & $\begin{array}{l}\text { Action-oriented, not just policy-oriented; } \\
\text { may involve multiple goals and multiple } \\
\text { fora within broader processes of regional } \\
\text { governance }\end{array}$ \\
\hline $\begin{array}{l}\text { Dynamism } \\
\text { over time }\end{array}$ & $\begin{array}{l}\text { Both episodic/single } \\
\text { issue and ongoing }\end{array}$ & $\begin{array}{l}\text { Multi-issue framing and relationship building } \\
\text { that allow regional resilience to adjust to } \\
\text { shocks and emerging challenges over time }\end{array}$ \\
\hline
\end{tabular}

The idea of repeated (even conflictual) interactions and processes gets us to the issue of dynamism. While there is a sense in the literature that epistemic communities are episodic-involving getting experts together to address a single thorny policy issue-we use the term to refer to sustained groupings of regional actors. Such dynamism, in the form of repeated interactions, has been crucial to responding to shocks and longer-term structural changes in such places as Raleigh, San Antonio, Oklahoma City, and even Silicon Valley.

In the first column of Table I.I, we summarize key characteristics of the more traditional conception of epistemic communities as originally proposed by Haas (with some elaboration). ${ }^{\mathrm{r} 3}$ In the second column, we expand upon this original conception and identify key elements of what we call diverse and dynamic epistemic communities. The differences are rather straightforward. We see diverse and dynamic epistemic communities as having a broader membership base, an ability to accommodate multiple ways of knowing, a scope of action which stretches across multiple outcomes and conversational arenas, a desire to move beyond the episodic, and a capacity to handle conflict even as they facilitate a sense of common destiny. 


\section{Structures, Norms, and Individuals}

As we hope is now clear, policy frameworks, stakeholder meetings, and community engagements may be evidence of an epistemic community, but we are talking about something far deeper and more ingrained in how a region operates. Indeed, behind the governance processes we will explore are regional "cultures" that often have to strain against the national norms and institutional incentives that have produced the divisive politics and unequal labor markets described at the beginning of this chapter. Indeed, interjurisdictional collaboration goes against the grain of local government fragmentation, inequality, and the Tieboutian service-based sorting into cities segregated by race, income, and amenities that characterizes most metropolitan regions in the United States. Thus, in trying to understand how these diverse and dynamic epistemic communities form, we need to pay particularly close attention to the development of regional social norms as well as the institutional structures and incentives that can underpin (or undermine) them.

This in turn requires a fundamental rethinking of traditional economic assumptions about human and social behavior. After all, economics often assumes exactly the sort of atomistic individuals among whom cooperation would be short-lived, sorting would be economically efficient, and social norms would play little role in shaping agent behavior. Yet in the cases we examine we see instances in which voters go against their seeming short-term interest, supporting pre-K for disadvantaged kids in San Antonio or investment in resuscitating Oklahoma City's downtown. We discover the importance of "Michigan nice" in explaining elite commitment to broadening opportunity in Grand Rapids, and we stress how the pride that Raleigh's leaders had in racially integrating its schools may have spilled over to other concerns. We note that the stories leaders tell themselves in regions that work tend to become similar (or normative) over time: collaboration as a keyword in San Antonio, the Triple Helix as the guiding principle for development in Raleigh, the rejection of Oklahoma City as a location for a United Airlines maintenance hub as a prompt to reexamine the area's quality of life.

More broadly, then, diverse and dynamic epistemic communities are about discovering and structuring processes to recreate a sense of the commons and of the common good. This perspective builds on and contributes to the broad literature on the commons-which has proffered evidence that cooperation and reciprocity are possible but which 
sometimes struggles to specify the processes in which such social norms are created (Benkler 20I I). In our work below, we stress roots, relationships, and reason: that is, how sinking roots in a region for the long haul, recognizing and working with diverse constituencies and multiple actors over time, and striving to resolve issues through reasoned dialogue actually creates change within as well as between the relevant actors. Transformed by interactions with each other, the very identities of actors shift: they come to see doing good and planning for the regional future as fitting a set of standards and norms they hold for themselves and others.

We should emphasize-particularly given the literature on regional collaboratives and public-private partnerships-that we are not necessarily talking about formally institutionalized processes of collaboration or interaction. Such formal processes may help underpin diverse epistemic communities (as in Salt Lake City and Sacramento, cases discussed below as instances of planning-driven community building), and institutional incentives and infrastructures can help either to maintain or to erode epistemic communities over time. But ultimately the processes of producing collective knowledge and common ground that we are examining are rooted in communication between people over long periods of time that may only partially and temporarily correspond to existing organizational structures and may be better characterized as “communities of practice" (Wenger I998).

\section{MAKE THE ROAD BY TALKING}

So how do we explore this interaction between equity, growth, and community? Below, we offer a road map to the book, outlining the chapters and what we hope to accomplish in each. The chapters build logically on one another. We start by establishing the econometric plausibility of our case and then turn to describing the quantitative and qualitative methods used to select cases. After that, we walk through the cases themselves, and we close by returning to the general lessons that emerge from the research, particularly about the importance of developing a new way for communities in a region to talk together about their common future.

That said, we are also aware that some readers might not fully enjoy or appreciate the discussions of hazard ratios, Cox regressions, and $z$-scores that animate chapters 2 and 3. Frankly, we don't quite understand that reaction-we tend to rejoice when there is a bounty of data and methods, and we hope that this volume actually illustrates how to 
effectively blend quantitative and qualitative approaches. However, we do not want to lose anyone along the way, and so we offer relatively simple explanations of the statistical work in the introductory and closing sections of each of those chapters; we also include a statistical appendix that contains a data panel for each region, to which we refer more sparingly in the text itself.

In any case, chapter 2 begins our argument by trying to establish some link between the dimensions of social disconnection and growth and equity outcomes. We do this by first reviewing research on the growth-equity relationship, including studies that make the link at both the international and interregional levels. We then describe our own work on the impacts of income inequality and various measures of social distance on regional economic sustainability, stressing that the ability to sustain employment growth over time is important because it can help regions and people avoid the long-lasting social and economic disruptions that occur as a result of economic downturns.

To look at the factors associated with long-term growth, we borrow from the methodology used in a recent study by the International Monetary Fund to examine the relations between various variables and the likelihood of falling out of "spells" of growth (which we measure as increases in employment). Looking at I 84 metropolitan areas between $\mathrm{I} 990$ and $20 \mathrm{II}$, we find that the single largest factor that seems to curtail job growth is initial inequality; not far behind in their impact are racial segregation and metropolitan fragmentation. We also find that city-suburban political polarization has a negative impact. We bring all this together to suggest that building community—that is, overcoming fragmentation-may indeed be critical for resolving regional challenges and spurring more equitable and more sustainable growth.

Chapter 3 describes the case-study selection process. As we explain, we wanted to look at both cases where equity and growth come together, to see whether an epistemic community was present, and cases where knowledge communities were reportedly present and were or were not yielding good results. Given that, we first worked from an extensive set of data on job and earnings growth on the one hand and income distribution and poverty reduction on the other to determine which of the largest 192 regions (by population) performed well over a thirty-year period. (We also checked this against the end points for median household income and the Gini coefficient to ensure that we weren't picking up above-average performance from an abysmal starting point that closed the period with a nearly abysmal end point.) 
From a wide range of possibilities, we chose eleven metropolitan areas, including a set of three in California and a set of three in North Carolina. (This was done in the hope that it would control for state laws and politics and allow for any metro divergence in governance to be more rooted in local regional cultures. As it turns out, less was gleaned from those controls, something that suggests more regional autonomy that even we expected, a topic discussed at more length in chapter 3.) We then entered the field, after developing a protocol aimed at understanding regional social norms around collaboration and conflict as well as the particular processes of regional information sharing, knowledge development, and knowledge interpretation across diverse constituencies. In each region, we conducted interviews with leaders from a wide range of constituencies, eliciting examples of collaboration and conflict, as well as looking at whether there were broadly shared sources of information for understanding both the region's economy and broad social conditions in the region.

Chapters 4 through 7 explore what we found-and they are organized around a sort of typology of regional epistemic communities that emerged in the course of the research. Chapter 4 , for example, takes up instances in which there were quite explicit planning processes meant to actually create a shared knowledge community at the metropolitan level. One of the clearest examples of this is in the Salt Lake City metro, in which a nonprofit planning group called Envision Utah has helped create a deep sense of regional consciousness about population and housing growth strategies and decisions. We also look at the Sacramento metro, a place where a "Blueprint process" was actually undertaken by the local council of governments to help the region's residents recognize their common and interconnected fate, particularly around issues of transportation, land use, and housing development.

Chapter 5 takes up a different sort of epistemic community: one in which regional stewardship is more or less driven by business elites. Here, we look at three case studies: Grand Rapids, Charlotte, and Oklahoma City. We suggest that the first two show some of the limits of this type of approach. Charlotte, for example, is home to a storied set of business leaders who were eager to make it the exemplar of the New South in terms of both race relations and economic vitality. Its very success has brought a wave of newcomers who do not appreciate the history as much, and with old norms eroding, so too are key elements of civic culture, as well as the trajectory of economic growth. Grand Rapids is among the most paternalistic of our cases. There, interviewees 
even spoke of the wealthy entrepreneurs who provide regional leadership as "fathers"-and while its trajectory was positive through the I980s and I990s, the region stumbled in the 2000 s as manufacturing declined.

On the other hand, Oklahoma City shows what can happen when elite leadership decides to respond to a shock with a commitment to dynamic change. After the region suffered the indignity of a major company's turning down significant tax breaks for relocating thereprimarily because the quality of life was so bad that the company's executives were worried that they would not be able to attract and keep workers-Oklahoma City leaders undertook a conscious effort to reverse the damage of suburban sprawl to the urban center and bring about a major revitalization of the downtown. The effort included a willingness to increase taxes-in a heavily Republican region-and while the drivers and deciders may have hailed from the elite, significant attention was paid to incorporating populations of higher social need and less political clout.

While all of our case studies explore the role of conflict, that is the central theme of chapter 6. Here, we consider three cases: Greensboro, Fresno, and San Antonio. In the first of these, we note how wildly divergent visions of the region-with whites hoping that Blacks would "just get over it," while Black memories of Jim Crow and Klan violence remain remarkably vivid-have conspired to limit the evolution of a diverse and integrated epistemic community. In Fresno, we note how both structural factors and a history of conflict have led to both poor outcomes and fragmented politics. While there are some hopeful signs in Fresno-a new general plan emerging from the city holds the promise of addressing sprawl and promoting compact development in the longneglected urban core-these cases could be read as simply suggesting that conflict is bad for your region's economic and epistemic health. But that is not necessarily the case.

Sometimes conflict can lead to collaboration. As it turns out, this is one of the main lessons from San Antonio. The region is currently heralded (and heralds itself) as a model of collaboration-and it has recently won a slew of federal designations under the Sustainable Communities Initiative, the Promise and Choice Neighborhoods programs, and most recently the Promise Zone effort. San Antonio has also made concrete progress on improving living standards and being more inclusive, as evidenced by its record (relative to the South) on measures of growth and distribution. But it came to what now seems like a positive 
set of outcomes through a set of sharp challenges to traditional centers of power by a highly mobilized set of minority constituents. This suggests that diverse epistemic communities can involve skirmish and struggle as well as conversation and consensus-and it is a point worth noting, given the need to lift up difficult issues of inequality in the contemporary United States.

Chapter 7 helps us think more about these national issues by looking at three places where the new knowledge economy has also involved knowledge communities: Silicon Valley, Raleigh, and Seattle. Silicon Valley hosts a sort of poster child for regional stewardship, Joint Venture Silicon Valley; however, a recent rise in globalization, inequality, and residential separation has helped detach leaders from the region in ways that are worrisome. Raleigh, on the other hand, more or less exemplifies the notion of a diverse and dynamic epistemic community with clear norms and a shared story. Its leaders often describe its growth lodestar as the Triple Helix (of which the three strands are university, government, and business), and long-timers consider one of its crowning achievements the desegregation of the school system (something that is now under threat from newcomers to the region). We close our casestudy examination with Seattle, home to a mature process of consensus building through mediated gatherings of diverse sector leaders to share and interpret data together on regional issues. Coupled with a unique focus on equity-partly stemming from a strong history of multi-ethnic and multi-racial organizing during the Civil Rights era-this "Seattle process" has led to many accomplishments, including (as we mentioned above) the city's adoption of a joint labor-business proposal for the country's highest minimum wage.

In chapter 8 , we try to synthesize the lessons of the case studies. We begin with a discussion of how the processes we unveil in our cases cannot easily be understood in the confines of traditional economic thinking, particularly models based on atomistic and disconnected actors (a point touched on above). We argue for a new microfoundational approach that recognizes how social norms and identities influence behavior and inform collaboration (or a lack thereof)—and we use that framework to suggest that diverse and dynamic epistemic communities involve transformations in actors as well as transactions between actors.

We then specifically focus on the conditions under which knowledge communities emerge, including: the role of shocks (such as rejection by an outside firm in the case of Oklahoma City or the pressures of future growth in the case of Salt Lake City); the presence or absence of formal 
governance structures (highlighting here, for example, the difference between the role of a metropolitan planning organization in Sacramento versus the privately initiated Envision Utah); and the impact of social movements and civic culture (for example, the emergence of principled conflict in the case of San Antonio or the commitment to process and conflict resolution in Seattle). Finally, we uncover from the cases what might be termed the mechanics of community building, including the development of shared knowledge and agendas, the need to frame issues in an inclusive way, and the importance of the development of collaborative leadership with a commitment to place.

In chapter 9, we try to explore the implications of this work for future research on regional economic and social trajectories. We suggest that diverse and dynamic epistemic communities are important in and of themselves since they contribute to a sense of civic membershipand that they can also enhance growth, innovation, and inclusion at the metropolitan level. While we acknowledge that much in this causal chain remains to be specified and also stress that there is not a fail-proof path from consensus to prosperity, we also suggest that such communities at least raise the likelihood of securing positive results. We then ask how such communities can be replicated across metropolitan areas, lifting up both nonprofit efforts like those of the Brookings Institution and PolicyLink and the innovative Sustainable Communities Initiative of the Obama administration. We note that challenges to replication are several, including the fact that connecting groups in a knowledge community is aided by a sense of place (so how does that work when there are many places?) and that some metropolitan regions may be either cursed or blessed by path dependence (cooperation breeds cooperation, conflict breeds conflict, and making the turn from one road to another is difficult).

We close the book by considering how the lessons learned might inform a more productive approach to the national crises of subpar job growth, worsening inequality, and political polarization-another sort of triple helix-with which we began this introductory chapter. We argue that diverse and dynamic knowledge networks can provide exactly the norms, standards, and (place) identities that can better link equity, growth, and community. Because they can generate genuine care for others, help participants develop communicative processes to balance competing needs, and forge a lived sense of common destiny, they provide the framework for achieving "win-win" solutions rather than Social Darwinist destruction. 
As Yochai Benkler insists in his path-breaking volume, The Penguin and the Leviathan: How Cooperation Triumphs over Self-Interest (20II), talk is not actually cheap; it requires effort, and it can help change hearts and minds in ways that encourage collaboration rather than zero-sum competition. Another world-one which fosters both innovation and inclusion, both economic growth and social justice-is indeed possible, but getting there will involve a different set of regional and national conversations. We hope this volume will contribute to that new dialogue about economic theory, policy practice, and our American future. 